\title{
A simple spectrophotometric method for the determination of urea in blood and urine
}

\section{T. K. WITH, TOVE DREYER PETERSEN, AND BIRGIT PETERSEN From the Central Laboratory, Svend- borg County Hospital, Denmark}

Several methods for determining urea in blood and urine are in use in clinical laboratories, but none is ideal in mass routine analysis. The spectrophotometric method based on a modified Ehrlich reagent proposed by Watt and Chrisp (1954) for pure solutions is therefore of interest because it can be modified for use in mass clinical analyses of blood and urine. Brown (1959) has modified the method for use on blood, but his procedure involves treatment with urease as well as spectrophotometric measurement and is hardly simple enough for routine clinical pathology laboratories. In this laboratory a modified Watt and Chrisp method has been used as a routine procedure for a year, and proved simple and reliable except in specimens from patients receiving sulphonamides or para-aminosalicylic acid, when it is unsatisfactory. Such specimens are easily recognized because of the atypical colour reaction (bright citrus colour) with the modified Ehrlich reagent. Other laboratories might therefore be interested in a detailed description of the technique.

\section{REAGENTS}

(1) SOMOGYI's ZINC SULPHATE SOLUTION Crystalline zinc sulphate, $12.5 \mathrm{~g}$., dissolved in $125 \mathrm{ml}$. $0.25 \mathrm{~N}$ sulphuric acid and diluted to $1,000 \mathrm{ml}$. with distilled water.

(2) $0.75 \mathrm{~N}$ SODIUM HYDROXIDE

(3) ALCOHOLIC EHRLICH REAGENT p-Dimethylaminobenzaldehyde (analytic), $20 \mathrm{~g}$., dissolved into $1,000 \mathrm{ml}$. $96 \%$ alcohol. To this solution is added $100 \mathrm{ml}$. concentrated hydrochloric acid (analytic) and mixed.

(4) STANDARD SOlution Urea, $100 \mathrm{mg}$., is dissolved in distilled water, $100 \mathrm{ml}$., in a measuring flask.

\section{PROCEDURE FOR BLOOD}

Twenty-four millilitres of reagent (1) are run from a burette into a $100 \mathrm{ml}$. Erlenmeyer bottle. To this is added $3 \mathrm{ml}$. whole blood (stabilized by oxalate), the bottle is shaken to obtain complete haemolysis, and $3 \mathrm{ml}$. of reagent (2) added and the mixture shaken again. It is then filtered through a special filter (Schleicher and Schull No. $589^{3}$, Blauband) to remove the precipitated proteins. (It is important to use a suitable filter paper because the

Received for publication 10 May 1960. usual laboratory filters may give falsely increased values. Of the clear and colourless filtrate $10 \mathrm{ml}$. is pipetted int a $25 \mathrm{ml}$. measuring flask and $10 \mathrm{ml}$. reagent (3) addedf After mixing dilute with distilled water to the mark and renew mixing. After 10 minutes the mixture is ready for reading. The colour is stable, according to Watt an Chrisp, for 11 days.

\section{READING}

The reactions are read in a spectrophotometer at $420 \mathrm{~nm}$ with a blank prepared in the same way as the reactiofy mixture but with $3 \mathrm{ml}$. of distilled water instead of $3 \mathrm{~mm}$ of blood. The urea standard (reagent 4) is treated in the same way as the blood. Cuvettes of $1 \mathrm{~cm}$. thickness ar $\vec{p}$ suitable.

If $p, s$, and $b$ are the extinctions of the sample, this standard, and the blank respectively, the urea concens tration is

$$
100(\mathrm{p}-\mathrm{b}) /(\mathrm{s}-\mathrm{b}) \mathrm{mg} . / 100 \mathrm{ml} \text {. }
$$

A Hilger Uvispec photoelectric spectrophotometer waఖ used in this laboratory, as attempts to use a Bausch an 9 Lomb Spectronic were unsuccessful. This is in good agreement with the finding of Brown (1959) that कै Coleman Junior spectrophotometer was not suitable fo $\vec{r}$ reading the Watt and Chrisp reaction.

\section{DETERMINATION IN URINE}

The procedure is exactly the same as for blood, the onlo difference being that if the concentration is above $1,00 \underline{Q}$ $\mathrm{mg} . / 100 \mathrm{ml}$. the reaction has to be repeated on a dilute $\bar{\Phi}$ sample because Beer's law is not valid for concentration above this limit. The urine filtrate is quite colourless wit年 the technique described.

\section{COMMENT}

The blank extinction is high compared with that of the reaction mixture and may vary somewhat from day tQ day for the same Ehrlich reagent. For different batches of Ehrlich reagent the blank extinction may vary betweep $0 \cdot 070$ and $0 \cdot 170$. According to our experience Ehrlich reagents giving a blank extinction below $0 \cdot 100$ are une suitable. The high blank value is a drawback, but the method is, in spite of this, sufficiently accurate for clinicas purposes.

To test the clinical reliability of the method 200 dupli: cate analyses were performed, one with the modified Watt and Chrisp method and one with the hypobromite method of Van Slyke and Kugel (1933). In the diagrane the analyses with the Watt and Chrisp method are plottefo along the abscissa, those with the Van Slyke and Kuge? method along the ordinate. It is easily seen that the points are scattered evenly on both sides of the identity line. Alb the analyses shown in this diagram were routine clinica $\mathbb{D}^{\circ}$ analyses. The diagram shows that the deviations betweer the two methods are too small to be of any clinical signi 2 ficance. Serum creatinine determinations have been made on all samples taken for blood urea for a year, ranging between 10 and 20 samples every day, and there has in alg 


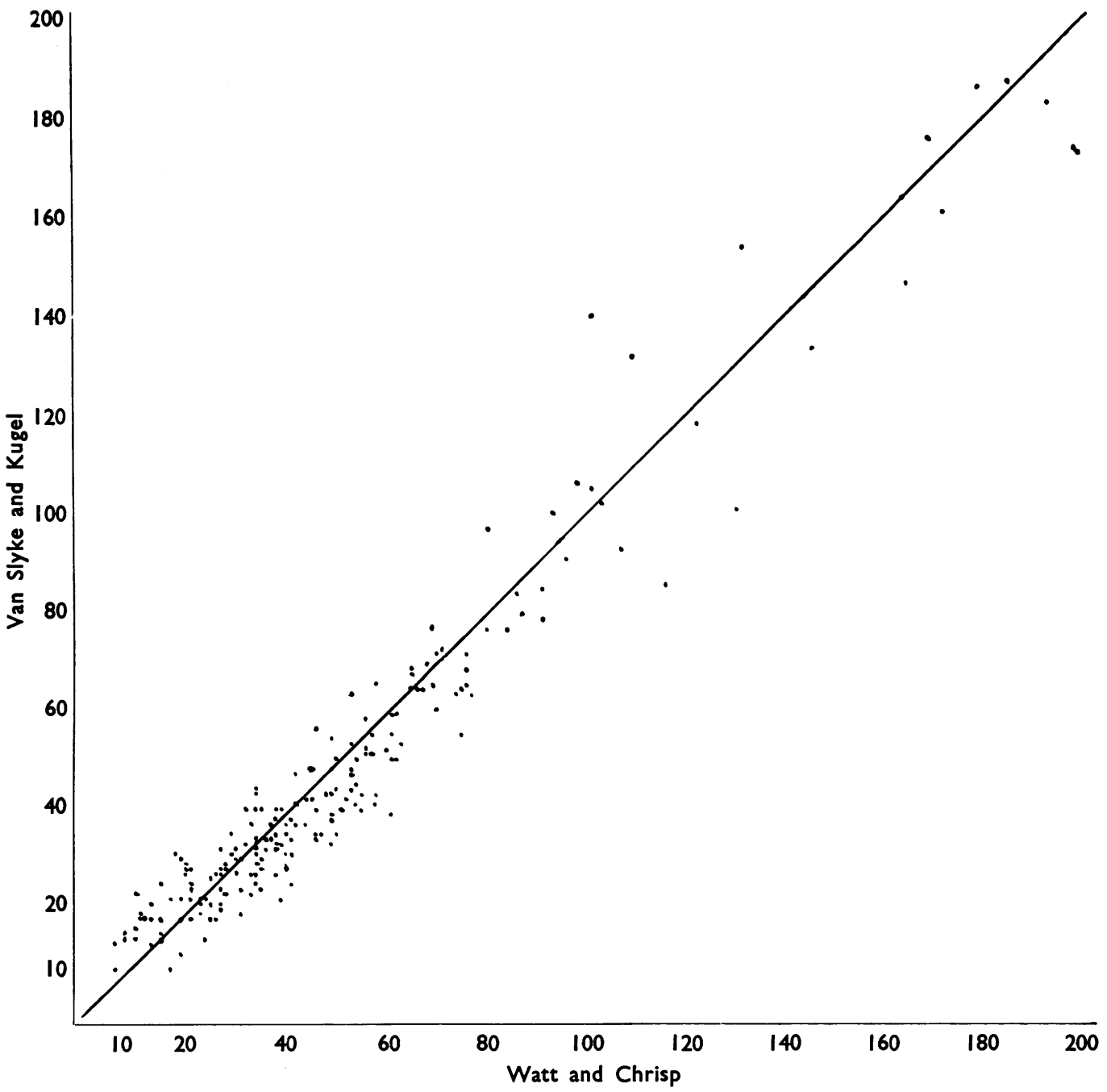

cases been reasonable agreement between the creatinine determination and the blood urea determined by Watt and Chrisp's method. All pathological values were controlled by double analysis with the Van Slyke and Kugel method and no clinically significant disagreement was encountered. The only exceptions were patients receiving sulphonamides or P.A.S.

\section{REFERENCES}

Brown, H. H. (1959). Analyt. Chem., 31, 1844.

Van Slyke, D. D., and Kugel, V. H. (1933). J. biol. Chem., 102, 489. Watt, G. W., and Chrisp, J. D. (1954). Analyt. Chem., 26, 452.

\section{ADDENDUM}

Since this paper has been printed we have learned that W. Daubenmerkl (personal communication) has elabor- ated a modification of our method. He read the extinction at $435 \mathrm{~nm}$. instead of $420 \mathrm{~nm}$. By reading at this wavelength instead of at the maximum $(420 \mathrm{~nm})$, the extinction of the blank value decreases to about $1 / 7$ while the specific extinction (extinction of test solution minus extinction of blank) decreased by only about $40 \%$. Thus it is possible to read the extinction with the test solution against the blank instead of reading both with water as blank, a modification which saves time. Also, this modification makes it possible to read the reaction in a simpler and cheaper type of instrument, e.g., the Bausch and Lomb Spectronic, whereas the reading with our original technique had to be performed in an instrument with a quartz prism and quartz cells. The accuracy of the method becomes much better at the lower range by reading at $435 \mathrm{~nm}$. instead of $420 \mathrm{~nm}$.

The considerable advantages of Daubenmarkl's modification is illustrated by the following table: 


\begin{tabular}{|c|c|c|c|c|c|c|}
\hline \multirow[b]{2}{*}{$\begin{array}{l}\text { Sample } \\
\text { No. }\end{array}$} & \multirow[b]{2}{*}{$\begin{array}{l}\text { Van } \\
\text { Slyke }\end{array}$} & \multicolumn{4}{|c|}{ CONCENTRATION (MG./100 ML.) } & \multirow[b]{2}{*}{$\begin{array}{l}\text { Spectronic } \\
\text { Reading } \\
\text { at } \\
435 \mathrm{~nm} \text {. }\end{array}$} \\
\hline & & $\begin{array}{l}\text { Watt and } \\
\text { Chrisp } \\
\text { Reading } \\
\text { at } \\
420 \mathrm{~nm} .\end{array}$ & $\begin{array}{l}\text { Watt and } \\
\text { Chrisp } \\
\text { Reading } \\
\text { at } \\
435 \mathrm{~nm} .\end{array}$ & $\begin{array}{l}\text { Sample } \\
\text { No. }\end{array}$ & $\begin{array}{l}\text { Uvispec } \\
\text { Reading } \\
\text { at } \\
435 \mathrm{~nm} .\end{array}$ & \\
\hline 1 & 19 & 30 & 14 & 1 & 28 & 29 \\
\hline 2 & 41 & 73 & 38 & 2 & 28 & 30 \\
\hline 3 & 97 & 126 & 102 & 3 & 21 & 24 \\
\hline 4 & 32 & 50 & 28 & 4 & 29 & 31 \\
\hline 5 & 97 & 137 & 107 & 5 & 21 & 36 \\
\hline 6 & 72 & 103 & 70 & 6 & 146 & 141 \\
\hline 7 & 29 & 38 & 21 & 7 & 126 & 116 \\
\hline 8 & & & & 8 & 54 & 55 \\
\hline 9 & 116 & 155 & 133 & 9 & 185 & 178 \\
\hline 10 & 23 & 26 & 18 & 10 & 312 & 275 \\
\hline 11 & 27 & 17 & 23 & & & \\
\hline 12 & 48 & 47 & 47 & & & \\
\hline 13 & 36 & 55 & 29 & & & \\
\hline
\end{tabular}

With this valuable modification the method of Watt and Chrisp comes within the reach of laboratories with modest equipment and attains the same grade of accuracy as the other routine laboratory procedures for blood urea besides being much more suitable for routine clinical pathology than the other available methods.

It must, however, be emphasized that extreme care is necessary in preparing the reagents, that high quality distilled water is required, and that fresh reagent (4) has to be used every week.

\section{A method for the collection of saliva}

\section{P. J. COUSINS ${ }^{1}$ From the Hospital for SicR Children, Great Ormond Street, London}

The collection of saliva from normal adults and children $\overrightarrow{\vec{H}}$ unless they are very young-presents no difficulty, bu where the patient is unable to use (or, as in one cases considered it rude to spit for any reason) a sputun receiver the collection presents a problem.

During a study of saliva from children with phenyin ketonuria (Cousins, Philips, Stroud, Wise, and Woolf 1960), a simple method of collection was adopted. A pasteur pipette with a bulb was cut short and a piece of polythene tubing of $2 \mathrm{~mm}$. bore affixed. The end of the polythene tube was warmed and pushed on to the pipett $\bar{z}$ tip, this having been similarly warmed; on cooling the joint was found to be very firm. The tubing was cut, so that its length was $6 \mathrm{~cm}$., the cut being diagonal across the tube. This end was warmed until pliable and therp squashed against a glass plate, thus forming a thickened and wide orifice approximately $4 \mathrm{~mm} . \times 2 \mathrm{~mm}$.

The patient was in one of two positions depending ore the degree of cooperation:

(1) The lateral position of the head while lying flat assistance in holding the head is necessary in cases of bact cooperation.

(2) Normal sitting position; assistance is necessary onl $\overrightarrow{\overrightarrow{0}}$ in the case of the very young.

The pipette is introduced $(a)$ to the cheek wall, and (b) under the tongue. Saliva can then be collected by normal pipettage. Amounts of the order of 2 to $3 \mathrm{ml} / \mathrm{A}$ can be collected in a comparatively short time and transferred to a stoppered test-tube (Exelo $10 \mathrm{~cm} . \times 1 \mathrm{~cm} \frac{\mathrm{O}}{3}$ most useful).

The best times for collection are just before a feed or at least two hours afterwards, there being no con₹ tamination by food residues at these times.

The advantages of such a pipette are:

(1) Should the patient bite down on the pipette no harmo is done, the portion in the mouth being polythene.

(2) No trauma occurs using polythene.

(3) Stimulation of salivary glands is easily effected.

(4) Polythene is easily cleaned and the pipette is easily and quickly cleaned in water.

(5) Such a pipette has a longer life than an ordinary bulb pasteur pipette.

\section{REFERENCE}

Cousins, P. J., Phillips, S. J., Stroud, C. E., Wise, J., and Woolf, C L. (1960). Amino Acids of Sweat and Saliva in Phenylketonuria In preparation.

Received for publication 26 May 1960.

'Present address: Royal National Orthopaedic Hospital, Brockley Hill, Stanmore, Middlesex. 